\title{
ADVERSE EFFECT OF COMBINED ORAL CONTRACEPTIVE PILLS
}

\author{
AKSHARA SHUKLA ${ }^{1}$, ROHITASH JAMWAL ${ }^{2}$, KUMUD BALA ${ }^{1 *}$
}

${ }^{1}$ Amity Institute of Biotechnology, Amity University, Uttar Pradesh, Sector-125, Noida, India. ${ }^{2}$ Department of Biomedical and Pharmaceutical Sciences, University of Rhode Island, Kingston, USA. Email: kbala@amity.edu

Received: 09 August 2016, Revised and Accepted: 20 September 2016

ABSTRACT

Oral contraceptive (OC) pills contain estrogen and progestin that are synthetic analogs of natural hormones. These synthetic hormones affect the hypothalamus-pituitary-gonadal axis of the female reproductive system. There are many types of contraceptives; most of the OC pills prevent pregnancy by inhibiting ovulation. Estrogen and progestin are two female reproductive hormones that are critical. Typically, estradiol is produced by growing follicle (ovaries) which stimulates the hypothalamus to produce the gonadotropin-releasing hormone, which further stimulates the anterior pituitary to produce follicle-stimulating hormone (FSH) and luteinizing hormone (LH). LH production triggers the ovulation. Similarly, the progesterone is produced by corpus luteum (ovaries), which triggers the production of FSH and LH. There are many types of progesterone available. Long-term usage of synthetic estrogen and progesterone can disturb the balance between the level of these hormones in the body. This imbalance may lead to severe side effects such as breast cancer, cervical cancer, thrombosis, direct impact on the brain, and infertility.

Keywords: Estrogen, Progesterone, Contraceptives, Herbal contraceptives.

(c) 2017 The Authors. Published by Innovare Academic Sciences Pvt Ltd. This is an open access article under the CC BY license (http://creativecommons. org/licenses/by/4. 0/) DOI: http://dx.doi.org/10.22159/ajpcr.2017.v10i1.14565

\section{INTRODUCTION}

Contraception is a method to prevent unwanted pregnancy. Combined oral contraceptives (COCs) have become a popular method of birth control due to their contraceptive efficacy and good tolerability profile [1]. These pills contain hormones that act on the reproductive system of female leading to contraceptives such as estrogen and progesterone. OCs are the combination of estrogen and progestin or only progestin. Over the years, OCs have developed through gradually reducing the dose of ethinylestradiol (EE) and introducing 17- $\beta$ estradiol, and various generations of progestin [2]. There are manytypes of estrogen and progesterone being used in pills like mestranol is a class of estrogen, and the 3-methyl ether of EE and norethynodrel is a type of progestin; its dose was $9.85 \mathrm{mg}$ per pill initially. In clinical studies, the efficiency of contraceptive was excellent, but this drug caused many side effects such as nausea, dizziness, headaches, stomachaches, and vomiting; these are the symptoms that had presented by the $17 \%$ women undergoing the clinical studies. Though, the death of a female had been reported who was taking the contraceptive pills in 1961. Although after so many years, OCs have developed by reducing the dose of estrogen and by discovering a new generation of progestins, and other routes of COC administration have been developed [3]. The findings of the previous research show some severe side effects of these pills. Thus, this short study is focused on the overview of the female reproductive system and its regulation, hormonal contraceptive pills, mechanism of action of these drugs, and side effects of OC pills.

\section{OVERVIEW OF FEMALE REPRODUCTIVE CYCLE}

The balance between estrogen and progesterone handles the development and maintenance of the female reproductive system. Cellular differentiation is regulated by progesterone while estrogen controls cell proliferation. Thus, uterine endometrium has 3 phases (Fig.1)

1. The follicular phase (estrogen dominant) is a growth phase where uterine glands grow and proliferate

2. During secretory (luteal) phase, (progesterone dominant) glands get tightly coiled, and secrete

3. During menses, spiral arteries constrict, and endometrium sloughs.

\section{REGULATION OF REPRODUCTIVE HORMONES IN FEMALE}

The hypothalamus is responsible for the secretion of gonadotropinreleasing hormones $(\mathrm{GnRH})$, which then stimulates the anterior pituitary to release follicle-stimulating hormones (FSH) and luteinizing hormones (LHs). FSH stimulates follicle growth, maturation of ovum leading to the release of estradiol from follicles. High levels of estradiol for a sufficient period stimulate sudden secretion of LHRH (GnRHpositive feedback), which induces a surge of LH (and FSH) secretes from the anterior pituitary (Fig. 2). LH surge leads to ovulation and assists the development of corpus luteum. Corpus luteum then releases progesterone. Increased levels of estrogen and progesterone will signal anterior pituitary and hypothalamus to stop the secretion of FSH and LH. The resulting negative feedback leads to deterioration of corpus luteum, which further decreases the amount of estrogen and progesterone [5].

The contraceptive pills work on the same hormonal axis mentioned above. These drugs modulate the normal condition of this hormonal regulation, which delays the follicle development in females. There are different categories of hormonal contraceptives and different mode of administration. Although, this study is focused only on COC pills and progesterone-only pills.

\section{CATEGORY OF HORMONAL CONTRACEPTIVES PILLS}

Previously, administration of COCs used to deliver a dose of high EE or mestranol along with progestin, resulting in increased risk of cardiovascular disease. However, the therapeutic combinations of COC have substantially changed over the past few decades (Fig. 3). Current COCs contain a low dose of EE or estradiol (E2) combined with new progestins, and many alternatives or nonoral routes of administration have been evolved. Besides, progestin-only contraceptive pills are a contraceptive method that may be the better option for women with several routes of administration are available these days [6].

\section{ORAL ROUTE OF ADMINISTRATION}

OCs can be categorized into two main categories:

- COC pills and

- Progestin-only pills (POPs).

\section{COCS PILLS}

Synthetic estrogen (with high dose) and androgenic progestin like norethisterone acetate or norethindrone had been marketed as the first COC. The present COCs deliver low doses of EE every day. E2 valerate 
and dienogest have been newly approved in Europe and the USA as quadriphase OC. Another monophasic COC that combines E2 with nomegestrol acetate, a progesterone-derived progestin, is now being marketed in several countries in Europe [7-9].

\section{Estrogen in COC}

The dose of estrogen has been decreased by drug companies to reduce the risk of cardiovascular disorders. The estrogen component, EE or $17 \alpha$ estradiol is used in COCs available these days (Table 1). Over the years, the dose of EE has reduced from 50 to $30-35 \mathrm{mg}$ and gradually to $20-15 \mathrm{mg}$. Pills are now segregated into higher and lower than $30 \mathrm{mg}$ dose of EE. This reduction has been made feasible due to the accessibility of new classes of progestin. In the 1970s, the concept arose to use the natural $17 \beta$ estradiol in COCs, although no satisfactory formulations were available for years. In few cases, the pills containing $17 \beta$-E2 were contraceptive, but females showed low tolerance experiencing excessive bleedings. There are two combinations have been commercialized containing estradiol (E2). Selective estrogen receptor modulators are under development, which has estrogenic activity on bone and endometrium but antiestrogenic activity on the breast, e.g., estetrol [3].

\section{Progestins in COC}

In the different combined pills available nowadays, the progestin component in the pill inhibits LH peak, decreases ovarian sensitivity to FSH, and therefore, decreases estradiol production. The estrogenic component regulates endometrium proliferation and compensates estrogenic deficiency induced by the antigonadotropic effect of the progestin. Progestins are classically characterized according to their structural origins. They bind to progesterone receptors, but progestins may also bind to other steroid receptors such as androgen, glucocorticoid, and mineralocorticoid receptors. Most of the progestins contained in COCs were initially derived from testosterone and are called 19-nortestosterone derivatives. Norethisterone is an estrone, and norethisterone acetate and norethynodrel are gonanes. Few pills containing first-generation progestins are still available. Their side effects such as acne, oily skin, and decreased high-density lipoprotein, mainly due to their androgenic properties, are the primary cause for their progressive withdrawal. Over the years, progestins with less androgenic effects have been developed (Table 2). Levonorgestrel (LNG) and norgestrel are second-generation progestins. Thirdgeneration progestin includes desogestrel (DSG), with its active metabolite 3-keto-DSG (also named etonogestrel), norgestimate (and its active 17-deacetylated metabolite, norelgestromin [NGMN]), and gestodene (GSD) [3].

Different progestins used in COCs are derived from progesterone. Molecules such as chlormadinone acetate, cyproterone acetate (CPA), and medroxyprogesterone acetate are called pregnane derivatives, as they are derived from $17-0 \mathrm{H}$ progesterone [10]. Some newer progestins have been available more recently in OCs such as drospirenone (DRSP). This progestin possesses antimineralocorticoid and weak androgen proprieties. Dienogest is a hybrid progestin, derived from the estrane group but does not exert the androgenic effects of the testosterone derivatives. A Cochrane review evaluated the effectiveness and side effects of different progestogens [11]. In this comparative study, 13,923 participants were included in a total of 30 trials enabling 16 comparisons. The conclusion of this Cochrane Review mentions that women using COCs containing second-generation progestogens may be less likely to discontinue than those using COCs containing first-generation progestogens. Based on one small double-blind trial, third-generation progestogens may be preferable to second-generation preparations concerning bleeding patterns, but further evidence is needed [3].

Millions of women have used estrogen and progestins as effective COCs. OCs modify surrogate markers such as lipoproteins, insulin response to glucose, and coagulation factors that have been associated with cardiovascular and venous risk. EE exerts a stronger effect that natural estradiol (E2) on hepatic metabolism. New progestins with high specificity have been designed to avoid interaction with other receptors and prevent androgenic, estrogenic, or glucocorticoid-related side effects. The risks and benefits of new progestins used in contraception depend on their molecular structure, the type and dose of associated estrogen, and the delivery route [3]

\section{Progestin-only contraceptive pills (POPs)}

POPs delivers a very low concentration of progestin every day (norethindrone, LNG, or DSG). While the developments of OCs pills are based on progestin-only components, recently POPs are less widely used than COC as a result of their negative uterine tolerance [12]. Though, POPs may be an attractive contraceptive choice for women with contraindications to COCs (Table 3).

\section{ALTERNATIVE (NONORAL) MODE OF ADMINISTRATION}

These types of contraceptives provide steady supplies of hormones. They can be delivered in a combination of estrogen and progestin or progestin only.

\section{Combined contraceptives}

There are two types of other (non-oral) mode of administration available: Patch and vaginal ring. The patch (transdermal) consists of EE along with NGMN and the vaginal ring consists of EE along with etonogestrel.

\section{Progestin-only contraceptive}

Currently, there are three major routes of nonoral administration of contraceptives which are frequently used in the USA and Europe [3]

Many synthetic hormonal contraceptives are available with different brand names, but these all contain synthetic estrogen and progesterone and having severe side effects. The details of few synthetic contraceptive drugs are mentioned in Table 4.

\section{ADVERSE EFFECT OF SYNTHETIC CONTRACEPTIVE PILLS}

It has been reported that $\mathrm{OC}$ pills may cause many side effects in a long run, and authors have discussed a few of those side effects in this article.

\section{Table 1: Two type of combinations of estradiol [3]}

\begin{tabular}{ll}
\hline Active ingredients & Classification of components \\
\hline Quadriphasic COC-E2 & E2 valerate-synthetic estrogen, \\
valerate+dienogest & metabolized into 17 bE2 \\
Monophasic COC-17b & Nomegestrol acetate-progestin \\
E2+nomegestrol acetate &
\end{tabular}

COC: Combined oral contraceptive

Table 2: Different generations of progestin used in COCs [3]

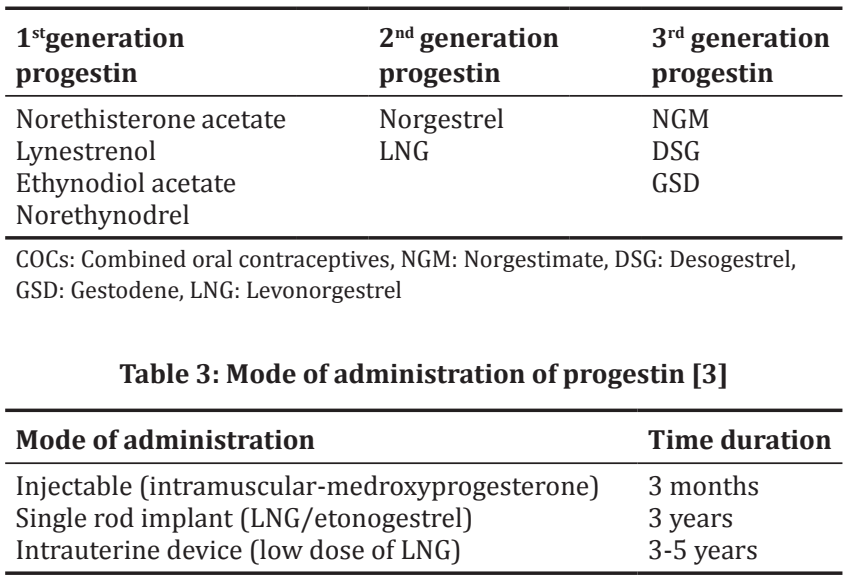

LNG: Levonorgestrel 
Table 4: List of synthetic hormonal contraceptive pills available, their mode of action and their side effect

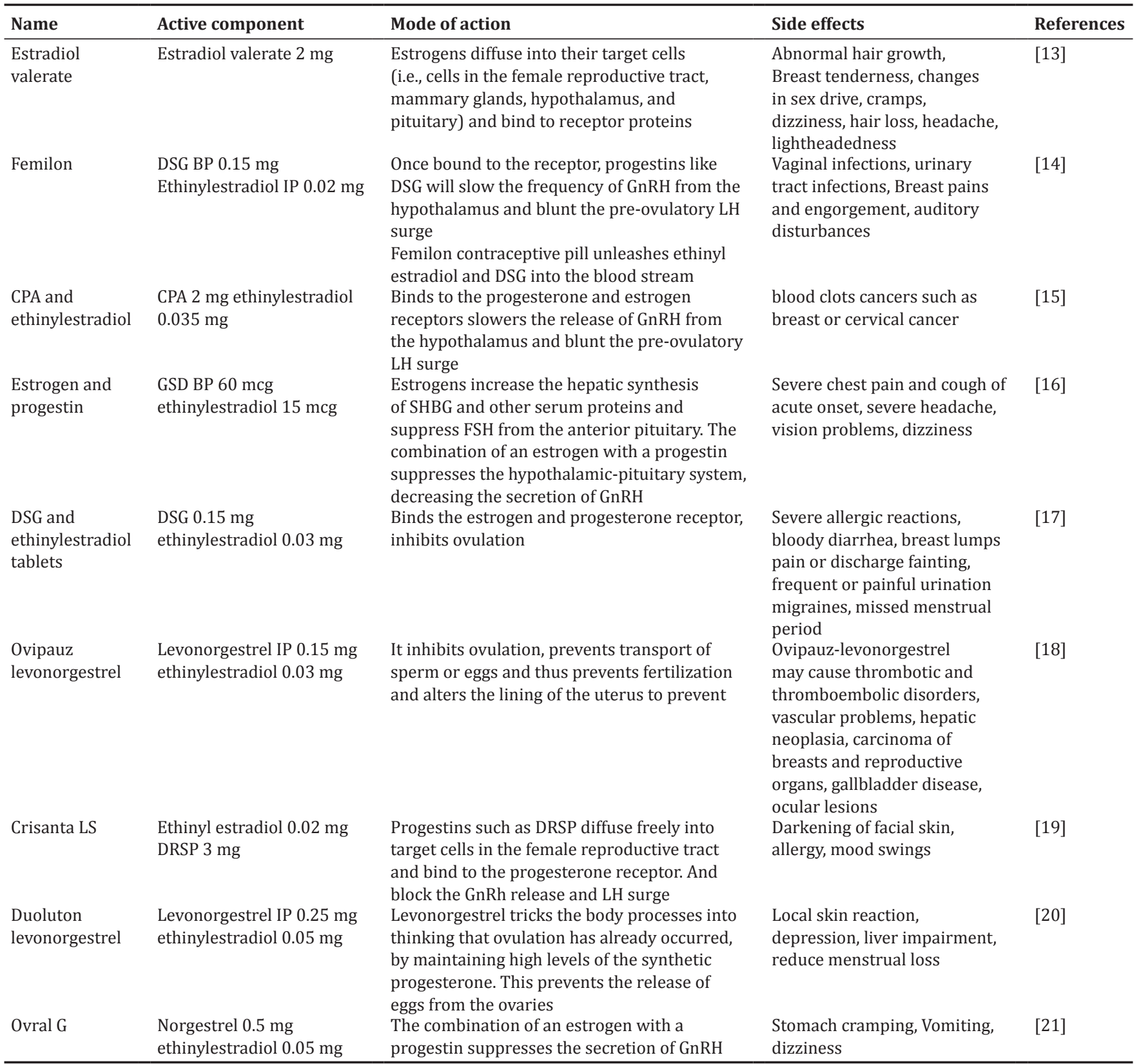

DRSP: Drospirenone, CPA: Cyproterone acetate, DSG: Desogestrel, GSD: Gestodene, SHBG: Sex hormone binding globulin, GnRH: Gonadotropin-releasing hormone

\section{Effects on brain structure}

Adult brain structure is subject to dynamic changes with age. These changes differentially affect brain areas, such as gray matter volumes in some regions, decline more strongly with age than others. An agerelated strong decline has been demonstrated in the prefrontal cortex, as well as the hippocampus. Recent results showed that regional gray matter volumes in the prefrontal cortex, as well as the cingulate anterior gyrus, are larger in mixed samples of androgenic and antiandrogenic OC users compared to nonusers [22]. These regions are already larger in women when compared to men. However, regional gray matter volumes of OC users were also greater in the cerebellum, hippocampi, parahippocampus, and fusiform gyri [23]. Those regions are on the average larger in men compared to women. Results from rodent hippocampi suggest that these volume increase may be attributed to an increase in synaptic spin density mediated by estrogen receptors [24], but an increase in astrocyte volume in response to estradiol has also been suggested [13].

\section{Hormonal contraceptives and risk of venous thromboembolism} (VTE)

It has been reported that VTE risk is related to COC [25]. The risk of VTE is higher during the $1^{\text {st }}$ year of use depending on the different combinations of COCs. Recently, new formulations of OCs and nonoral routes of administration have been evaluated in the context of VTE risk [26-28]. Based on the epidemiological findings, the risk of VTE is higher among those using 30-35 mg of within different types of progestin as compared to COC containing LNG [28]. With the same doses of EE (30-35 mg), the COC-containing DRSP, EE CPA, DSG, or GSD also increased the risk of VTE as compared to COC-containing LNG. It has also been reported that use of nonoral routes of combined contraceptives, patch, or vaginal ring is also associated with a higher VTE risk compared with the second-generation pills [28]. The changes found to be more deleterious to users of this new progestin than among LNG users. In combination with EE, these new progestin appears to induce resistance to activated protein C (APC), which is a surrogate marker of VTE risks. The effect on APC resistance of 


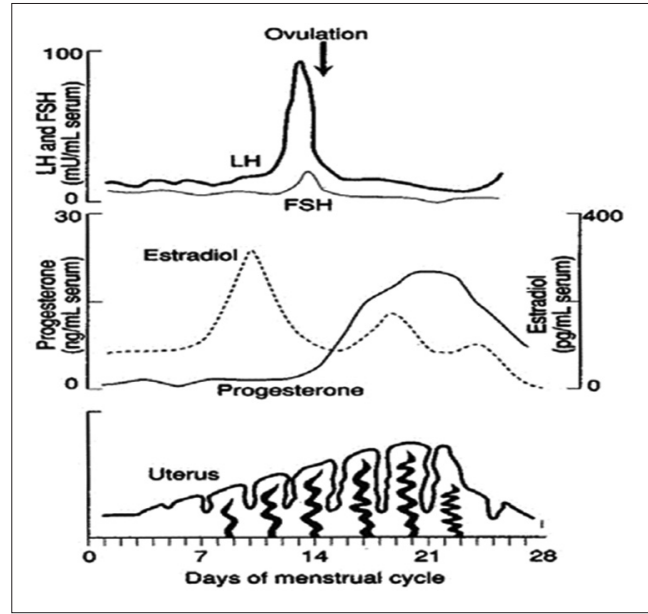

Fig. 1: Phases of female reproductive cycle without hormonal support [4]

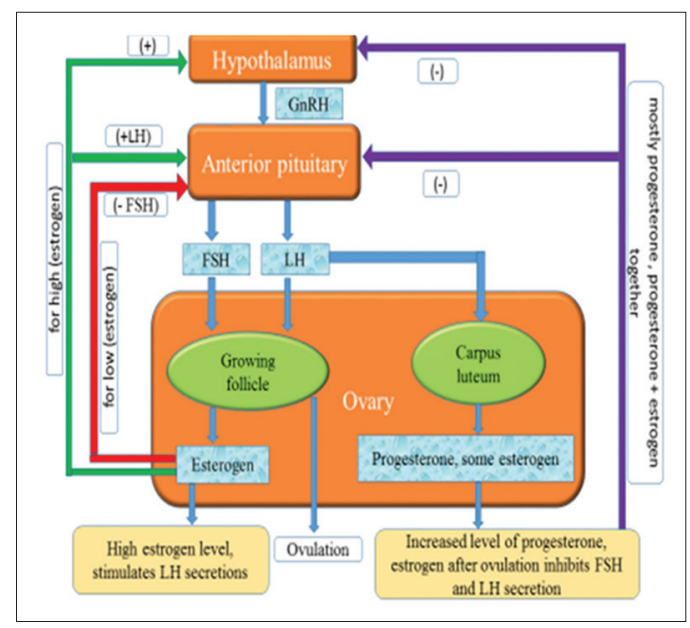

Fig. 2: Regulation of hypothalamus-pituitary-gonadal axis [5]

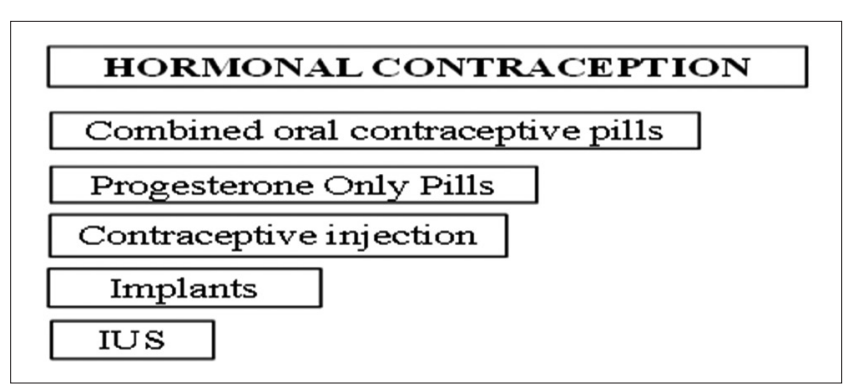

Fig. 3: Categories of hormonal contraception [3]

the different molecules of progestin associated with the same EE dose has been clearly investigated. It has been found that acquired APC resistance (measured as the effect of APC on thrombin generation) may be related to the thrombotic effect of hormonal contraceptives. Sex hormone binding globulin (SHBG), a carrier protein synthesized by the liver, has found to be positively correlated with APC resistance among pill users. It is, therefore, another useful pharmacological marker to predict the thrombotic venous safety of a combined contraception indirectly. Hence, SHBG appears to be higher among users of DSG, DRSP, and CPA containing pills as compared to those using LNG pills [29-31].

\section{CONCLUSION}

Contraceptive pills mainly work by inhibiting or delaying ovulation and up to some extent preventing fertilization and implantation. Several clinical studies have shown that COCs works primarily on either inhibiting or delaying ovulation. Millions of women in this reproductive age (14-45 years) are taking these medicines to delay pregnancy. Many of the women have experienced side effects after taking COCs or POPs such as spotting, weight gain or weight loss, nausea, breast tenderness, severe headache, depression, darkening skin, and vaginal infection. There is sufficient evidence in humans that combined oral estrogen-progesterone contraceptives are carcinogenic in nature. This assumption has made by increased risk for cancer of breast, cervical, and liver. However, experiments in animals have provided inadequate evidence for the carcinogenicity of progesterone, LNG, norgestrel, or progestin-derived contraceptive pills. These contraceptives act as LH receptor (LHR) and progesterone hormone receptor (PGR) inhibitors and thus in long-term usage interferes with the ovulation cycle which results in premature ovulation or delayed ovulation. However, herbal compounds have been found to work as partial inhibitors of LHR and PGR, and at the moment, they are being removed from the system, the ovulation cycle is retained. Collectively, there is a need to work for herbal analogs of these contraceptives which can be effective as well as safe.

\section{REFERENCES}

1. Klipping C, Duijkers I, Parke S, Mellinger U, Serrani M, Junge W. Hemostatic effects of a novel estradiol-based oral contraceptive: An open-label, randomized, crossover study of estradiol valerate/dienogest versus ethinylestradiol/levonorgestrel. Drugs R D 2011;11(2):159-70.

2. Christin-Maitre S. History of oral contraceptive drugs and their use worldwide. Best Pract Res Clin Endocrinol Metab 2013;27(1):3-12.

3. Hugon-Rodin J, Gompel A, Plu-Bureau G. Epidemiology of hormonal contraceptives-related venous thromboembolism. Euro J Endocrinol 2014;171(6):R221-30

4. Chernykh VB, Kurilo LF. Genetically controlled hormonal regulation of human sexual differentiation and reproductive system development. Russ J Genet 2001;37(11):1238-46.

5. Kong L, Tang M, Zhang T, Wang D, Hu K, Lu W, et al. Nickel nanoparticles exposure and reproductive toxicity in healthy adult rats. Int J Mol Sci 2014;15(11):21253-69.

6. Sitruk-Ware R, Nath A. Characteristics and metabolic effects of estrogen and progestins contained in oral contraceptive pills. Best Pract Res Clin Endocrinol Metab 2013;27(1):13-24.

7. Mueck AO, Sitruk-Ware R. Nomegestrol acetate, a novel progestogen for oral contraception. Steroids 2011;76(6):531-9.

8. Trémollieres F. Oral combined contraception: Is there any difference between ethinyl-estradiol and estradiol? Gynecol Obstet Fertil 2012;40(2):109-15.

9. Sitruk-Ware R, Nath A. The use of newer progestins for contraception. Contraception 2010;82(5):410-7.

10. Wu CQ, Grandi SM, Filion KB, Abenhaim HA, Joseph L, Eisenberg MJ. Drospirenone-containing oral contraceptive pills and the risk of venous and arterial thrombosis: A systematic review. BJOG 2013;120(7):801-10.

11. van Hylckama Vlieg A, Middeldorp S. Hormone therapies and venous thromboembolism: Where are we now? J Thromb Haemost 2011;9(2):257-66

12. Wright KP, Johnson JV. Evaluation of extended and continuous use oral contraceptives. Ther Clin Risk Manag 2008;4(5):905-11.

13. Jepson JH, Lowenstein L. Inhibition of the stem cell action of erythropoietin by estradiol valerate and the protective effects of 17-alpha-hydroxyprogesterone caproate and testosterone propionate. Endocrinology 1967;80(3):430-4

14. Korhonen T, Tolonen A, Uusitalo J, Lundgren S, Jalonen J, Laine K. The role of CYP2C and CYP3A in the disposition of 3-keto-desogestrel after administration of desogestrel. Br J Clin Pharmacol 2005;60(1):69-75.

15. Pham-Huu-Trung MT, de Smitter N, Bogyo A, Girard F. Effects of cyproterone acetate on adrenal steroidogenesis in vitro. Horm Res 1984;20(2):108-15.

16. Micevych PE, Mermelstein PG. Membrane estrogen receptors acting through metabotropic glutamate receptors: An emerging mechanism of estrogen action in brain. Mol Neurobiol 2008;38(1):66-77.

17. Gentile DM, Verhoeven CH, Shimada T, Back DJ. The role of CYP2C in the in vitro bioactivation of the contraceptive steroid desogestrel. J Pharmacol Exp Ther 1998;287(3):975-82.

18. Brama M, Gnessi L, Basciani S, Cerulli N, Politi L, Spera G, et al. Cadmium induces mitogenic signaling in breast cancer cell by an ERalpha-dependent mechanism. Mol Cell Endocrinol 2007;264(1-2):102-8. 
19. Krattenmacher R. Drospirenone: Pharmacology and pharmacokinetics of a unique progestogen. Contraception 2000;62(1):29-38

20. Attia AM, Ibrahim MM, Abou-Setta AM. Role of the levonorgestrel intrauterine system in effective contraception. Patient Prefer Adherence 2013;7:777-85.

21. Stegeman BH, de Bastos M, Rosendaal FR, van Hylckama Vlieg A, Helmerhorst FM, Stijnen T, et al. Different combined oral contraceptives and the risk of venous thrombosis: Systematic review and network meta-analysis. BMJ 2013;347:f5298.

22. Pletzer B, Kronbichler M, Aichhorn M, Bergmann J, Ladurner G, Kerschbaum HH. Menstrual cycle and hormonal contraceptive use modulate human brain structure. Brain Res 2010;1348:55-62.

23. Murphy DD, Cole NB, Segal M. Brain-derived neurotrophic factor mediates estradiol-induced dendritic spine formation in hippocampal neurons. Proc Natl Acad Sci U S A 1998;95(19):11412-7.

24. Spencer JL, Waters EM, Romeo RD, Wood GE, Milner TA, McEwen BS. Uncovering the mechanisms of estrogen effects on hippocampal function. Front Neuroendocrinol 2008;29(2):219-37.

25. Lidegaard O, Nielsen LH, Skovlund CW, Løkkegaard E. Venous thrombosis in users of non-oral hormonal contraception: Follow-up study, Denmark 2001-10. BMJ 2012;344:e2990.

26. de Bastos M, Stegeman BH, Rosendaal FR, Van Hylckama Vlieg A,
Helmerhorst FM, Stijnen T, et al. Combined oral contraceptives: Venous thrombosis. Cochrane Database Syst Rev 2014;3:CD010813.

27. Plu-Bureau G, Maitrot-Mantelet L, Hugon-Rodin J, Canonico M. Hormonal contraceptives and venous thromboembolism: An epidemiological update. Best Pract Res Clin Endocrinol Metab 2013;27(1):25-34.

28. Martínez F, Ramírez I, Pérez-Campos E, Latorre K, Lete I. Venous and pulmonary thromboembolism and combined hormonal contraceptives. Systematic review and meta-analysis. Eur J Contracept Reprod Health Care 2012;17(1):7-29.

29. Raps M, Helmerhorst FM, Fleischer K, van Hylckama Vlieg A, Stegeman BH, Thomassen S, et al. Sex hormone-binding globulin as a marker for the thrombotic risk of hormonal contraceptives: Reply to a rebuttal. J Thromb Haemost 2013;11(2):396-7.

30. van Vliet HA, Frolich M, Christella M, Thomassen LG, Doggen CJ, Rosendaal FR, et al. Association between sex hormone-binding globulin levels and activated protein $\mathrm{C}$ resistance in explaining the risk of thrombosis in users of oral contraceptives containing different progestogens. Hum Reprod 2005;20(2):563-8.

31. Sowell ER, Peterson BS, Thompson PM, Welcome SE, Henkenius AL, Toga AW. Mapping cortical change across the human life span. Nat Neurosci 2003;6(3):309-15. 